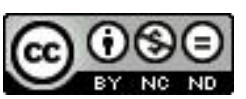

\title{
Um Estudo de Planos, Cilindros e Quádricas, na Perspectiva da Habilidade de Visualização, com o Software Winplot
}

\section{A Study of Planes, Cylinders and Quadrics, from the Perspective of Visualization Ability, with the Software Winplot}

\author{
Janine Freitas Mota* \\ João Bosco Laudares**
}

\begin{abstract}
Resumo
Este artigo é resultado de uma dissertação de Mestrado em Ensino de Matemática, cuja temática foi: estudo de planos, cilindros e quádricas. A metodologia utilizada contemplou os parâmetros da sequência didática, com exploração da habilidade de visualização. As sequências didáticas articulam teoria e prática, privilegiando o tratamento gráfico, utilizando seções transversais e curvas de níveis, com o objetivo de possibilitar ao estudante o esboço de gráficos com as mídias lápis e papel e o software Winplot. Foram propostas a estudantes do primeiro período do curso de licenciatura em Matemática. A análise qualitativa dos resultados evidenciou a forma como os estudantes realizaram as representações gráficas, suas reflexões, dúvidas e resultados, e também se verificou uma melhora significativa na postura dos mesmos, pois esses se manifestaram mais ativos no processo de aprendizagem. Foi observado que a articulação entre a equação (álgebra) e a figura (geometria) promoveu uma abordagem integrada entre Álgebra e Geometria, que é o foco da Geometria Analítica.

\footnotetext{
* Mestre em Ensino de Ciências e Matemática pela Pontifícia Universidade Católica de Minas Gerais (PUC-Minas). Professora da Universidade Estadual de Montes Claros (UNIMONTES), Montes Claros, MG, Brasil. Endereço para correspondência: Rua Manoel Bandeira, 1139, Planalto, CEP: 39404-035, Montes Claros, MG, Brasil. E-mail: janinemota@gmail.com.

** Doutor em Educação: História e Filosofia da Educação pela Pontifícia Universidade Católica de São Paulo (PUC-SP). Professor da Pontifícia Universidade Católica de Minas Gerais (PUC-Minas), Belo Horizonte, MG, Brasil. Endereço para correspondência: Rua Jornalista Moacir Andrade, 192, CEP: 30350-410, Belo Horizonte, MG, Brasil. E-mail: jblaudares@terra.com.br.
} 
Palavras-chave: Educação Matemática. Sequências Didáticas de Atividades. Planos. Cilindros. Quádricas.

\begin{abstract}
This article is the result of research on teaching mathematics that focused on the study of planes, cylinders and quadrics. The methodology included the parameters of didactics and explored visualization capabilities. The didactic sequence joins theory and practice, emphasizing graphing, using cross-sections and level curves, with the objective of allowing the student to draw graphs with pencil and paper as well as the software Winplot. The study was carried out with first-year university mathematics students. The qualitative analysis of the results showed how students performed the graphical representations, their thoughts, issues and results, and also pointed to significant improvement in students' attitudes, as they became more active in the learning process. It was observed that the relationship between the equation (algebra) and figure (geometry) promoted an integrated approach between algebra and geometry, which is the focus of analytic geometry.
\end{abstract}

Keywords: Mathematics Education. Teaching Sequences of Activities. Plans. Cylinders. Quadrics.

\title{
1 Introdução
}

As pesquisas na área de Educação Matemática promovem reflexões sobre como a forma tradicional de ensino pode ser inovada por meio de estratégias diferenciadas, que visem a uma melhor qualidade no processo de ensinoaprendizagem da Matemática.

A nossa prática profissional, com estudantes da Licenciatura em Matemática e cursos de Engenharias, revelou o quanto é difícil trabalhar os tópicos planos, cilindros e quádricas nas disciplinas Geometria Analítica ou Cálculo Diferencial e Integral, seja por reduzida carga horária para esses conteúdos, seja pela dificuldade que os estudantes têm na visualização geométrica no espaço tridimensional ou, na relação entre questões visuais e analíticas.

As dificuldades dos estudantes nos tópicos de geometria perpassam toda a educação básica, chegando ao ensino superior. Essa deficiência é evidenciada por vários pesquisadores em Educação Matemática, tais como Lorenzato (1995), Dante (1988) e Pavanello (1993). Essa defasagem gera dificuldades de aprendizagem, principalmente na disciplina Geometria Analítica e em tópicos do Cálculo Diferencial e Integral. 


\section{A pesquisa}

A nossa proposta compõe-se de uma sequência didática para o ensino dos tópicos: planos, cilindros e quádricas, na qual foi explorada a visualização e o traçado dessas figuras. Foram utilizadas interseções das mesmas com planos (cortes), obtendo-se as seções transversais. Para o traçado do esboço, foi feita uma análise da equação das superfícies e dos planos interceptos.

Dessa forma, as atividades propostas foram desenvolvidas articulando as mídias lápis e papel com ferramentas informatizadas. Foi selecionado o software Winplot, por ser um programa freeware (gratuito), executado no sistema operacional Windows, que permite uma dinâmica de rotação e translação de figuras, facilitando a visualização geométrica no espaço tridimensional com múltiplas representações.

O objetivo geral da pesquisa foi de propor atividades, que possibilitem ao estudante desenvolver a habilidade de visualização e representação de planos, cilindros e quádricas.

Dentre os objetivos específicos, destacamos: análise de livros didáticos de Matemática, Geometria Analítica e Cálculo; elaboração, avaliação e validação de uma sequência didática de atividades que desenvolva o pensamento geométrico, interligado aos aspectos teóricos e práticos das superfícies em estudo; articulação das representações algébrica e geométrica dessas superfícies; exploração das interseções de planos com superfícies cilíndricas e quádricas; seleção e análise da utilização de um software matemático no desenvolvimento da sequência didática.

A nossa questão de investigação foi subdividida em 4 (quatro) subquestões, para que ficassem claros os caminhos da pesquisa: (1) Como a habilidade de visualização das figuras espaciais: planos, cilindros e quádricas contribuem com o pensamento geométrico? (2) Como a utilização das seções transversais das superfícies podem contribuir para a visualização das mesmas? (3) Como a articulação entre as representações algébrica e geométrica pode contribuir para o desenvolvimento do processo de ensino-aprendizagem de planos, cilindros e quádricas na disciplina Geometria Analítica? (4) De que forma a utilização de um software contribui para o desenvolvimento da habilidade de visualização de figuras tridimensionais?

Os métodos utilizados na pesquisa foram: análise documental correspondente ao estudo dos tópicos Planos, Cilindros e Quádricas em obras de Geometria Analítica e Cálculo; elaboração, aplicação e avaliação de uma 
sequência didática de atividades. A metodologia proposta mostrou-se inovadora, pois intercala atividades que envolvem as mídias lápis e papel e o ambiente computacional.

O produto dessa pesquisa é constituído por um Caderno, contendo uma sequência didática de atividades, explorando o estudo gráfico de planos, cilindros e quádricas, com o software Winplot, apresentado na defesa da Dissertação.

Logo após o término do Mestrado, foi elaborado um Projeto de Pesquisa, aprovado pelo Fundo de Incentivo à Pesquisa - FIP/PUC-Minas, para editoração de um livro com o conteúdo da pesquisa. Esse Projeto foi desenvolvido durante um ano, com o apoio de bolsistas de iniciação científica, que pesquisaram uma melhor edição dos gráficos com o software Autocad. O Winplot traz deformações em alguns gráficos, especialmente, nas quádricas. Assim, a otimização da edição do livro exigiu a utilização do software Autocad. Para o desenvolvimento das atividades, foi sugerida a utilização do Winplot, que é um software livre de geometria dinâmica.

A editoração do livro será concluída em 2013. O produto da pesquisa está disponível, na íntegra e gratuitamente, na Biblioteca Digital de Teses e Dissertações da Pontifícia Universidade Católica de Minas Gerais (PUC-Minas), no endereço eletrônico www.pucminas.br no link Biblioteca e, brevemente, no livro editado.

\section{0 processo ensino-aprendizagem de geometria: visualização e pensamento geométrico}

O ensino de geometria tem sido pautado, ainda tradicionalmente, com definições e demonstrações de propriedades no tratamento formal de conceitos. Partindo de uma proposta mais progressista, Nasser e Sant' anna (2004) buscam a compreensão conceitual com o desenvolvimento do pensamento geométrico. Essas autoras analisaram, e tem divulgado no Brasil, o modelo de Van Hiele. Baseadas nesse modelo defendem o desenvolvimento da assimilação do conhecimento geométrico dos estudantes, a partir de um reconhecimento das figuras geométricas, de um nível básico até a percepção dos aspectos formais da dedução rigorosa, passando por níveis intermediários.

Embora o modelo de Van Hiele seja mais utilizado no nível básico de ensino, entendemos que esse também pode ser utilizado no nível superior, de maneira similar, pois, também no ensino superior, a aprendizagem de conceitos geométricos ocorre por níveis de compreensão - os estudantes atribuem 
significado a um conceito básico de forma gradual, observando regularidades e produzindo generalizações.

Na nossa pesquisa, tratamos especialmente dos 3 (três) primeiros dos 5 (cinco) níveis de Van Hiele, isto é, níveis de reconhecimento (visualização das figuras), análise (evidência nos conceitos, elementos e propriedades geométricas) e abstração (percepção de definições precisas, argumentação lógica informal e ordenação de classes de figuras geométricas). Tudo isso com o tratamento gráfico das figuras espaciais: planos, cilindros e quádricas. Passando por esses níveis, o estudante pode desenvolver habilidades que contribuam com o seu pensamento geométrico e facilitem o aprendizado de tópicos relacionados com geometria, a requerer a habilidade de visualização.

A imagem mental está associada à visualização dos objetos. Segundo Gravina (1996), o objeto geométrico é tratado como tendo duas componentes: uma conceitual e outra figural. A componente conceitual expressa propriedades que caracterizam uma classe de objetos, enquanto a componente figural corresponde à imagem mental que associamos ao conceito. Destacamos que a visualização é uma aptidão que está relacionada com a habilidade de gerar uma imagem mental, promover diversas transformações com objetos e reter alterações produzidas sobre o mesmo.

\section{Ensino e aprendizagem de planos, cilindros e quádricas}

Na literatura acadêmica especializada encontramos referência ao pensamento aritmético, ao pensamento algébrico e ao pensamento geométrico, que são fundamentais para a compreensão conceitual e a formalização em Matemática. Habilidades e competências são trabalhadas para explorar, conjeturar e raciocinar logicamente. Entretanto, a iniciação da aprendizagem da geometria na escola básica não é realizada de forma satisfatória, conforme destaca Pavanello (1993), dentre outros.

Dessa forma, quando o estudante inicia seus estudos em Geometria Analítica, definida como integração da Álgebra e Geometria, há uma dificuldade de interpretação e análise, pois o desconhecimento de propriedades de geometria plana e espacial prejudica a compreensão dos tópicos relacionados a essa disciplina. A falta desses conhecimentos fundamentais também pode acarretar dificuldades na visualização de objetos geométricos.

Para melhor compreensão de propriedades dos planos, cilindros e das quádricas e domínio de visualização de seus gráficos, é importante o traçado do 
esboço do gráfico em diversas posições e constituição de sólidos construídos a partir de figuras espaciais.

\section{A informática educativa no estudo de figuras espaciais}

O processo ensino-aprendizagem tem sido reformulado em mudanças, especialmente a partir das novas tecnologias da informação e comunicação, buscando promover mediação entre professor/aluno, aluno/aluno, segundo Moran (2000). Especialmente, os software de geometria dinâmica proporcionam possibilidades de exploração e experimentação pelo movimento das figuras, facilitando a visualização e a compreensão de propriedades das figuras planas e espaciais nos espaços de duas e três dimensões. Optamos pelo software Winplot que atende a essas características.

A dificuldade dos alunos em visualizar uma figura espacial pode ser atenuada com a exploração dessas figuras em diferentes posições e com diversificação de possibilidades de representação. A integração da mídia computacional, com o traçado utilizando lápis e papel, traz a possibilidade de uma melhor compreensão das figuras nos vários espaços, possibilitando, ainda, uma melhor interpretação da equação referente à mesma.

\section{A sequência didática}

As sequências didáticas possibilitam ao estudante construir um conhecimento significativo, ao mesmo tempo em que desencadeiam indagações, refutações e comparações, integrando as informações obtidas e descobertas.

Foram elaboradas, em nossa pesquisa, três sequências didáticas de atividades que articulam teoria e prática, propiciando a construção de significados, por meio de atividades de exploração e visualização, com base no esboço das superfícies no espaço - planos, cilindros e quádricas. Essas sequências didáticas foram desenvolvidas nos moldes de Zabala (1998), como uma maneira de encadear e articular as diferentes atividades ao longo de uma unidade didática, de forma que se possa analisar os resultados alcançados e as possíveis intervenções na execução das mesmas. As sequências foram organizadas da seguinte forma:

1. planos;

2. cilindros (quádricos e não quádricos);

3. quádricas; 
3.1 elipsoide / esferoide / esfera;

3.2 paraboloide elíptico;

3.3 hiperboloide de uma folha / hiperboloide de duas folhas;

3.4 cone quádrico;

3.5 paraboloide hiperbólico (sela).

O planejamento das atividades foi fundamentado, destacando as possíveis interações que poderiam ser estabelecidas entre sujeitos, pesquisador e o objeto de estudo. As estratégias de solução, para cada atividade, foram analisadas de forma a verificar o sucesso na execução das atividades e as contribuições cognitivas que essas trariam aos sujeitos da pesquisa. Também foram analisadas as conjeturas que poderiam ser levantadas e, posteriormente, validadas.

A sequência didática de atividades foi aplicada em um ambiente de sala de aula ( $1^{\circ}$ período do curso de Licenciatura em Matemática), como parte das atividades constantes da disciplina Geometria Analítica. A pesquisadora foi também a professora da disciplina.

Em todas as atividades elaboradas, focalizamos o traçado das superfícies, buscando proporcionar ao estudante um amadurecimento na desenvoltura do trabalho nos espaços bi e tridimensional. Exploramos, com intensidade, o significado dos parâmetros presentes nas equações, bem como a natureza das variáveis (livres ou não) e qual a interferência desses na representação gráfica da superfície.

A seguir, destacamos tópicos das atividades propostas.

\subsection{Atividade 1: planos}

Objetivo: analisar a variação dos parâmetros da equação do plano; traçar planos para facilitar o esboço das seções transversais.

Habilidade a ser desenvolvida: visualização de planos no espaço tridimensional.

A metodologia utilizada consiste em, inicialmente, trabalhar com a familiarização do espaço tridimensional, no que se refere à identificação dos octantes e, posteriormente, com a equação e o esboço do plano. Exploramos as variáveis, parâmetros e as características gerais da equação de plano. Sempre que possível, solicitamos que o estudante, inicialmente, fizesse o traçado dos gráficos de forma manual, considerando o espaço bidimensional, para que, posteriormente, pudesse partir para representação no espaço tridimensional. 
Por exemplo, para o traçado do gráfico de equação $x+y-2=0$, estabelecemos a seguinte sequência:

Considere a equação $x+y-2=0$

1. Como será a representação gráfica dessa equação considerando o (plano xy)? Faça o esboço do gráfico.

2. Essa equação é uma equação de plano. Dê os valores dos parâmetros.

3. Vamos descobrir como se dá a representação gráfica no . Siga os passos:

a) Complete a equação introduzindo a variável $\mathbf{z}$.

b) Dê as coordenadas das interseções da reta com os eixos $\boldsymbol{x}$ e $\boldsymbol{y}$ no sistema tridimensional.

c) Esboce o gráfico, abaixo, usando os interceptos.

Quadro 1 - Sequência de construção do gráfico do plano de equação.

Atividade 1 da pesquisa

Fonte: Mota (2010).

A seguir, propomos que o gráfico fosse plotado no software Winplot. Para tanto, foram dadas todas as orientações com relação aos comandos que deviam ser utilizados, conforme destacamos:

d) Plote o gráfico no Winplot:

Abra o Winplot. Acione a opção JANELA à 3-Dim

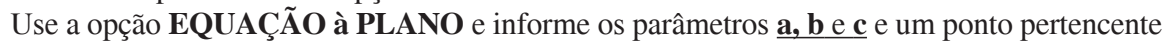
ao plano $\underline{(\mathrm{k}, \mathrm{m}, \mathrm{n})}$. Altere os valores $\mathrm{t}$ mín: $\mathbf{- 4}$; t máx: 4 ; u mín: -4 ; u máx: 4

Quadro 2 - Sequência de construção do gráfico do plano de equação no Winplot.

Atividade 1 da pesquisa

Fonte: Mota (2010).

Apresentamos, a seguir, o resultado do comando executado na tela do Winplot:

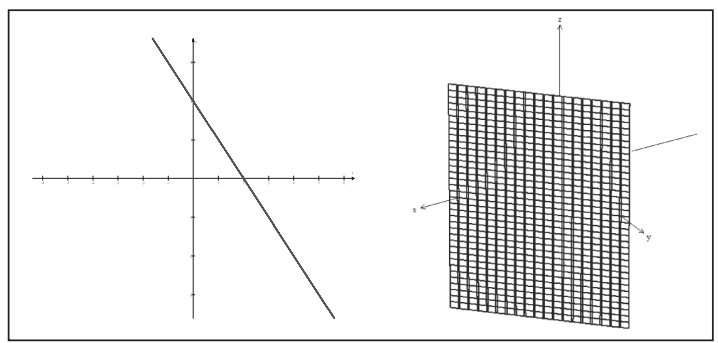

Figura 1 - Representação gráfica da equação da reta nos espaços bi e tridimensional. Fonte: próprio autor. 
Também foram exploradas famílias de planos. Como exemplo, ilustramos os planos plotados pelos estudantes $x+y+7=0 ; x+y+5=0 ; x+y-10=0$ com a equação geral $x+y+d=0$. Outra atividade proposta constitui-se em plotar a figura composta pelos planos $x=1 ; y=1 ; z=1$, no primeiro octante. A seguir, apresentamos o resultado na tela do Winplot:

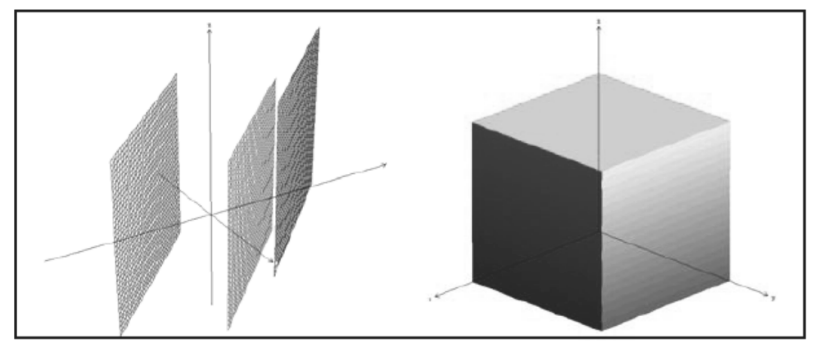

Figura 2 - Planos paralelos e superfície composta por planos paralelos aos planos coordenados.

Fonte: próprio autor.

\subsection{Atividade 2: cilindros}

Objetivo: identificar os vários tipos de cilindros, explorando suas equações.

Habilidade a ser desenvolvida: relacionar figuras dos espaços bi e tridimensional.

Nessa atividade também exploramos, de forma intensa, a relação entre a equação da superfície e sua representação geométrica, uma vez que muitos estudantes apresentam dificuldades em lidar com as diversas representações gráficas e algébricas de curvas. A metodologia utilizada consiste em, inicialmente, propor atividades que proporcionem o entendimento das definições iniciais sobre cilindro, seus elementos e classificação. Exploramos a classificação dos cilindros quanto à sua geratriz (retos ou oblíquos), quanto à forma de sua diretriz (parabólico, elíptico, circular, hiperbólico) e quanto à forma da sua equação: quádricos (apresenta pelo menos uma variável de $2^{\circ}$ grau e as outras de $1^{\circ}$ grau), não quádricos.

Apresentamos as equações de cilindros retos, para que o estudante fizesse o esboço dos gráficos manualmente, e, em seguida, pelo software Winplot, como a seguir. 
Esboçar, no papel, o cilindro circular com geratrizes paralelas a z:

a) Esboce o gráfico da curva de equação $x^{2}+y^{2}=4$ no plano $x y$.

Que curva essa equação representa?

b) No $\mathfrak{R}^{3}$, esboce o cilindro, usando a curva dada no item anterior.

Observe que teremos como variável livre a variável z. Que equações representam o cilindro gerado?

c) Plote no software Winplot o cilindro esboçado anteriormente.

Use as opções: EQUAÇÃO $\rightarrow$ IMPLÍCITA $\rightarrow$ (Aumente as dimensões do BOX.) $\rightarrow$ OK Clique em NÍVEIS $\rightarrow$ AUTO $\rightarrow$ MANTER MUDANÇAS.

d) Observando o cilindro traçado no Winplot, registre no papel os seguintes gráficos, no $1^{\circ}$ octante:

d.1) Trace a porção do cilindro limitada pelo plano $\mathrm{z}=6$, no $1^{\circ}$ octante.

d.2) Trace as curvas de níveis observadas.

d.3) Variando o valor de $\mathbf{z}$, que tipo de figura obtém-se nos planos paralelos a $\mathbf{x y}$ ?

d.4) Trace o sólido resultante, no $1^{\circ}$ octante, da intersecção do cilindro com o plano $\mathrm{z}=6$. (Hachure com cores diferentes os contornos visíveis das superfícies).

Quadro 3 - Fragmento da atividade. Traçado do cilindro de equação Fonte: Mota (2010).

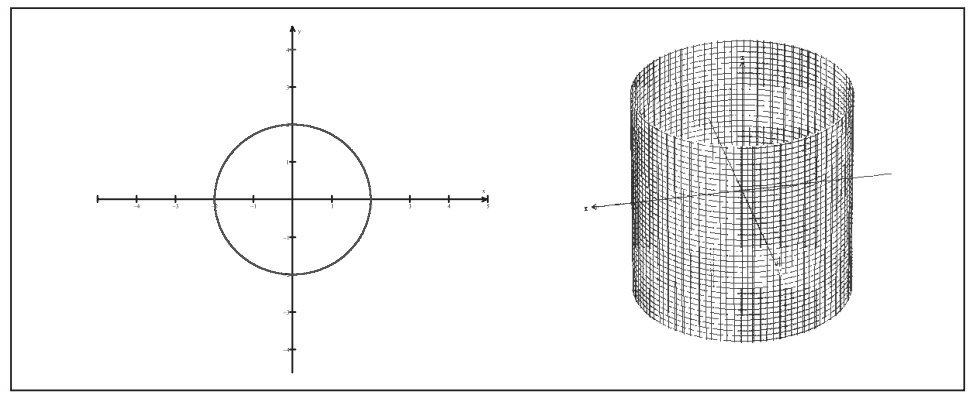

Figura 3 - Representação gráfica da equação $x^{2}+y^{2}=4$ nos espaços bi e tridimensional.

Fonte: próprio autor.

Ainda nessa atividade, exploramos outros tipos de cilindros quádricos e não quádricos, a porção dos cilindros limitados por planos, apenas no $1^{\circ}$ octante, as curvas de níveis paralelas aos planos coordenados e o sólido resultante, no $1^{\circ}$ octante, da interseção do cilindro com planos. O objetivo era que o estudante pudesse produzir as seguintes imagens no software Winplot: 


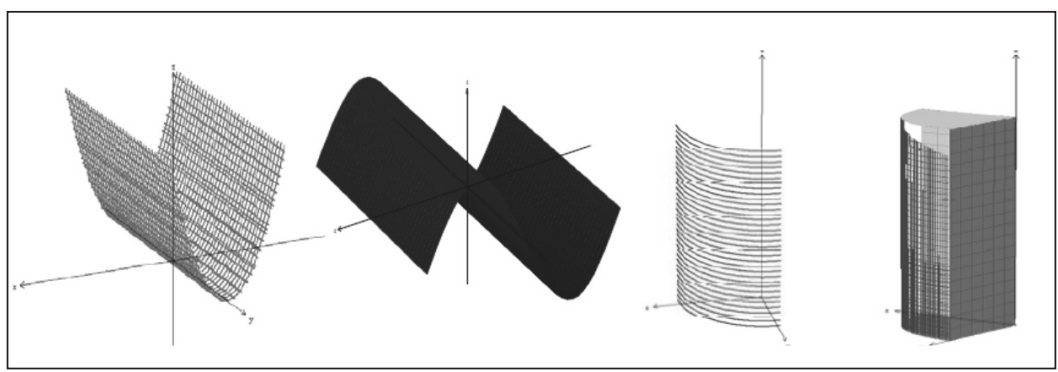

Figura 4 - Representação gráfica das curvas de níveis do cilindro de equação $x^{2}+y^{2}$ $=4$ e do sólido formado por este, no $1^{\circ}$. octante, limitado pelo plano $\mathrm{z}=6$.

Fonte: próprio autor.

Dessa forma, possibilitamos, ao estudante, a generalização das equações dos cilindros e a análise da relação dessas com a sua representação geométrica.

\subsection{Atividade 3: quádricas}

Objetivo: visualizar as superfícies quádricas pelas seções transversais. Habilidade a ser desenvolvida: relacionar as figuras e suas equações.

Nessa atividade exploramos a visualização das superfícies quádricas, as curvas de níveis e as seções transversais das superfícies, relacionando com as equações algébricas das mesmas.

Foram abordadas as quádricas: Elipsoide, Hiperboloide de uma folha e de duas folhas, Cone Quádrico, Paraboloides Elípticos e Hiperbólicos. A sequência de atividades foi desenvolvida, partindo do esboço das interseções da superfície com os planos coordenados, para se chegar ao esboço da superfície no espaço tridimensional.

A metodologia utilizada nessa atividade consiste em, inicialmente, destacar a definição das quádricas, abordando suas equações. Posteriormente, destacamos a classificação das quádricas, de forma que o estudante pudesse se familiarizar com os nomes das mesmas e sua visualização geométrica.

Como exemplo, apresentamos trecho da atividade em que propomos o esboço de um elipsoide: 
2.1 Esboçar o elipsoide de equação: $\frac{x^{2}}{4}+\frac{y^{2}}{9}+\frac{z^{2}}{1}=1$ :

a) Esboce as interseções da superfície com os planos coordenados $x y(z=0) ; y z(x=0) ; x z(y=0)$, de forma a obter as cônicas nos respectivos planos:

\begin{tabular}{|c|c|c|}
\hline Para $x=0$ & Para $y=0$ & Para $z=0$ \\
\hline Equação: $\frac{y^{2}}{9}+\frac{z^{2}}{1}=1$ & Equação: & Equação: \\
\hline Gráfico no plano: & Gráfico no plano: & Gráfico no plano: \\
\hline Cônica: elipse & Cônica & Cônica \\
\hline
\end{tabular}

Figura 5 - Fragmento da atividade. Esboço do elipsoide de equação $\frac{x^{2}}{4}+\frac{y^{2}}{9}+\frac{z^{2}}{1}=1$ Fonte: Mota (2010).

Propomos a identificação das curvas de níveis e o esboço do elipsoide no $1^{\circ}$ octante. Solicitamos a plotagem no Winplot, para que houvesse a comparação dos resultados das figuras obtidas. Apresentamos os resultados que os estudantes tiveram, na tela do computador:

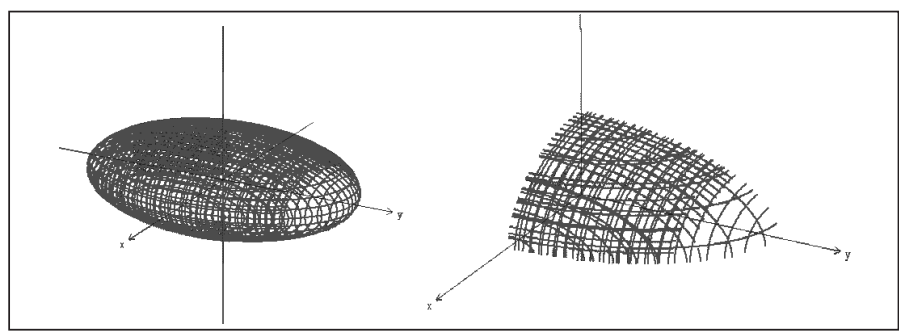

Figura 6 - Representação gráfica do elipsoide de equação: $\frac{x^{2}}{4}+\frac{y^{2}}{9}+\frac{z^{2}}{1}=1$, utilizando o software Winplot.

Fonte: próprio autor.

No trabalho com as quádricas, os estudantes puderam esboçar com lápis e papel e visualizar as seguintes imagens plotadas no software Winplot, sempre utilizando as seções transversais e curvas de níveis. 


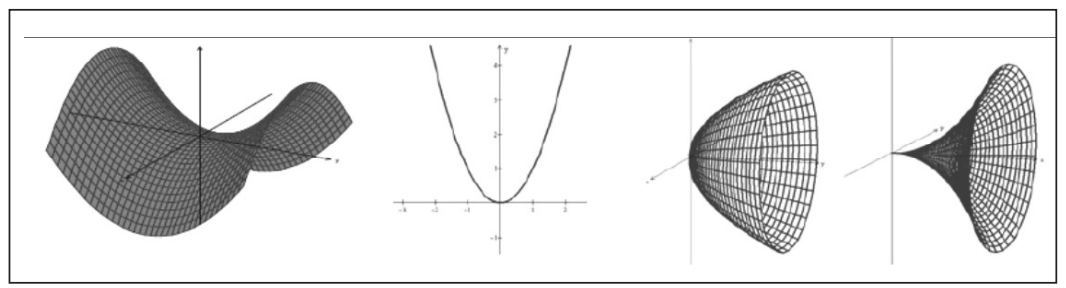

Figura 7 - Representação gráfica do Paraboloide Hiperbólico de equação $z=y^{2}-x^{2}$; parábola geradora de superfícies de revolução e superfícies de revolução geradas pela curva $y=x^{2}$

Fonte: próprio autor.

\section{Análise dos resultados obtidos}

Analisando as atividades, verificamos as atitudes e habilidades adquiridas, quanto ao pensamento geométrico pela visualização. Percebemos que, no início do desenvolvimento das atividades, alguns estudantes apresentaram dificuldades com relação à utilização do computador e à utilização do software Winplot, por terem pouca familiaridade com o computador. No entanto, aos poucos foram se familiarizando com as ferramentas mais utilizadas.

Ao esboçar as figuras, no papel, os estudantes tiveram sucesso. A seguir, apresentamos exemplos de esboços feitos pelos mesmos:

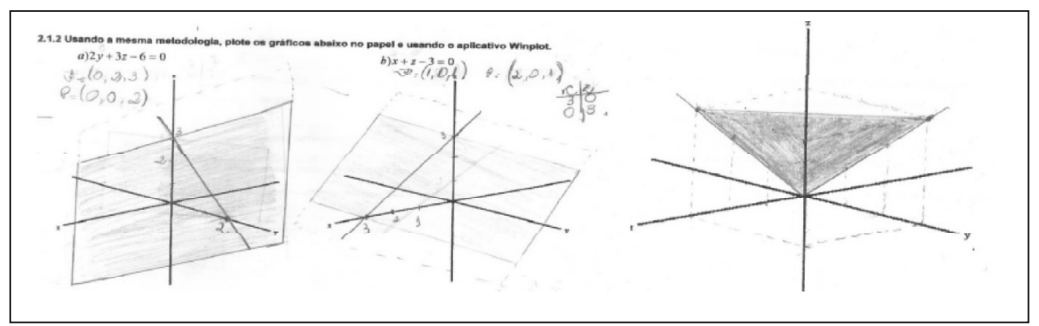

Figura 8 - Protocolo extraído do caderno de atividades de um dos estudantes.

Esboço de planos

Fonte: Mota (2010).

A maioria dos estudantes conseguiu fazer o estabelecimento da relação entre a representação algébrica e geométrica das superfícies em estudo.

Os estudantes esboçaram corretamente os cilindros com geratrizes paralelas aos eixos $x$ e $y$. A seguir, apresentamos os protocolos referentes aos gráficos traçados pelos estudantes: 


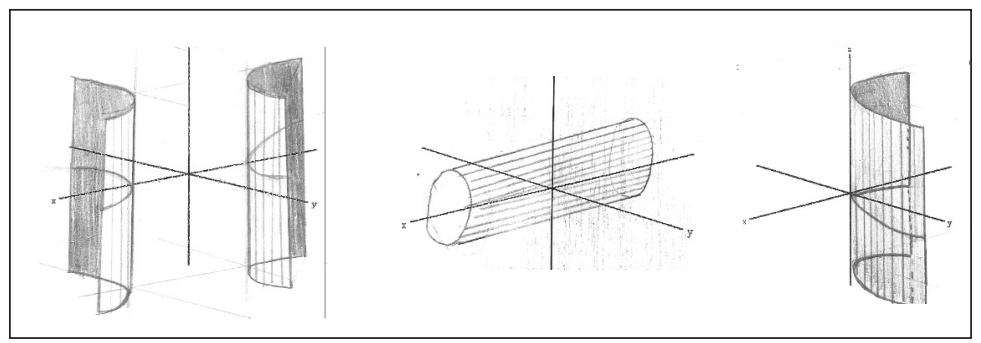

Figura 9 - Protocolos extraídos dos cadernos de atividades dos estudantes Fonte: Mota (2010).

Também tiveram sucesso no traçado do paraboloide pelas seções transversais.

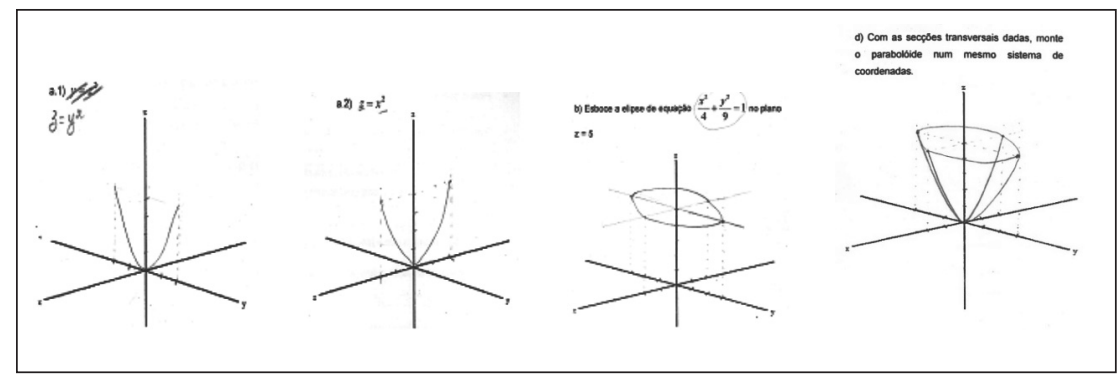

Figura 10 - Protocolos extraídos dos cadernos de atividades dos estudantes.

Fonte: Mota (2010).

\section{Considerações finais}

O saber-fazer, explorado em diversas situações e com diferentes superfícies, relacionando a equação (álgebra) à figura (geometria), favoreceu o desenvolvimento do pensamento relacional e uma melhor compreensão conceitual em Geometria Analítica. A fala do estudante, registrada a seguir, demonstra que a atividade possibilitou essa relação: com o software foi possível analisar as figuras em cima das equações. Observar os mínimos detalhes possíveis das figuras no espaço.

Zabala (1998), exemplificando e estruturando as unidades da sequência didática, propõe o diálogo professor/aluno para discussão de questões relacionadas ao tema, o que ocorreu na aplicação das atividades quando instigamos o estudante a usar sua intuição, fazer conjeturas e buscar sua elaboração mental da imagem gráfica que deveria esboçar no papel ou plotar 
pelo software. Percebemos que a visualização espacial foi melhorando, com menos dúvidas no final.

Segundo Machado (2008), a visualização é o desenvolver da habilidade de criação de imagens mentais, o que foi bastante explorado nas atividades propostas. Verificamos que ao tratar a informação figural, o estudante conseguiu conceituar, através de relações abstratas, representações em termos visuais.

A utilização das seções transversais das superfícies planas, cilindros e quádricas contribuiu para a compreensão das mesmas, uma vez que o estudante parte da representação plana para a representação espacial. Isso fez com que a dificuldade de visualizar e esboçar gráficos em três dimensões fosse minimizada ao longo das atividades, como destaca um dos estudantes: [...] a visualização é muito melhor e a gente participa mais na construção de figuras.

A articulação entre as representações algébrica e geométrica contribuiu para o desenvolvimento do processo de ensino dos tópicos em estudo. As atividades promoveram uma abordagem integrada entre Álgebra e Geometria, de forma que o foco na representação algébrica da superfície pudesse facilitar a compreensão de sua representação geométrica e vice-versa, conforme destaca o estudante com a fala registrada: o aprendizado foi um dos fatores mais importantes para mim. Apesar das minhas figuras (sic) não saírem bonitas eu consegui notar a diferença de cada figura, seja ela um cilindro, elipse, cone ou hipérbole, pois as equações são diferentes.

A interação entre as mídias possibilitou uma diversificação na sequência didática proposta. Segundo Borba e Penteado (2003), a informática não requer exclusividade nos processos didáticos, mas alternância entre aulas expositivas e atividades com as mídias.

A aplicação das atividades também revelou o grau de dificuldades dos estudantes em relação a tópicos da geometria básica, evidenciando o que foi também retratado nas pesquisas de Gravina (1996). As atividades elaboradas necessitavam de conhecimentos prévios, isso causou algumas dificuldades para determinados estudantes.

A pesquisa, trazendo a metodologia do esboço das superfícies com as seções transversais e as curvas de níveis, definiu uma série de itinerários e passos com uma aprendizagem mais efetiva. 


\section{Referências}

BORBA, M. C.; PENTEADO, M. G. Informática e Educação Matemática. 3. ed. Belo Horizonte: Autêntica, 2003.

\section{DANTE, L. R. Criatividade e Resolução de problemas na Prática Educativa}

Matemática. 1988. 192f. Tese (Livre Docência) - Universidade Estadual Paulista, Rio Claro, 1988.

GRAVINA, M. A. Geometria Dinâmica: Uma Nova Abordagem para o Aprendizado da Geometria. In: SIMPÓSIO BRASILEIRO DE INFORMÁTICA NA EDUCAÇÃO, 7., Belo Horizonte, 1996. Anais... Belo Horizonte: SBC, 1996. p.1-13. CD-ROM.

LORENZATO, S. Por que não ensinar Geometria? A Educação Matemática em Revista, Blumenau, ano 3, v. 1. n. 4, p. 3-13, jan./jun. 1995.

MACHADO, R. M. A Visualização na Resolução de Problemas de Cálculo Diferencial e Integral no Ambiente Computacional MPP. 2008. 289f. Tese (Doutorado em Educação) - Universidade Estadual de Campinas, Campinas, 2008.

MORAN, J. M. Ensino e Aprendizagem Inovadores com Tecnologias Audiovisuais e telemáticas. In: MORAN, J. M.; MASSETO, M. T.; BEHRENS, M. A. (Org.). Novas Tecnologias e Mediação Pedagógica. 8. ed. Campinas: Papirus, 2000. p. 11-66.

NASSER, L.; SANT'ANNA, N. F. P. Geometria segundo a teoria de Van Hiele. 4. ed. Rio de Janeiro: Projeto Fundão/Universidade Federal do Rio de Janeiro/Instituto de Matemática, 2004.

PAVANELLO, R. M. O abandono do ensino da geometria no Brasil: causas e conseqüências. Zetetiké, Campinas, ano 1, v. 1, n. 1, p. 7-17, 1993.

ZABALA, A. A Prática Educativa: unidades de análise. In: ZABALA, A. (Org.). A prática educativa. Porto Alegre: ArtMed Editora, 1998. p. 13-25.

Submetido em Agosto de 2012. Aprovado em Fevereiro de 2013. 